\title{
Factors Associated with Consumption of Diabetic Diet among Type 2 Diabetic Subjects from Ahmedabad, Western India
}

\author{
Mayur Patel', Ina M. Patel', Yash M. Patel', Suresh K. Rathi² \\ 'Swasthya Hospital, All India Institute of Diabetes and Research, Narainpura, Ahmedabad 3800I3, Gujarat, India; \\ ${ }^{2}$ Department of Community Medicine, SBKS Medical Institute and Research Centre, Sumandeep Vidyapeeth, \\ Piparia, Vadodara 39I 760, Gujarat, India
}

\begin{abstract}
This cross-sectional study assessed the current situation of and factors associated with consumption of diabetic diet among 399 type 2 diabetes mellitus (T2DM) subjects from Ahmedabad, Western India. The study was performed with diagnosed (at least one year old) diabetic subjects who attended the Department of Diabetology, All India Institute of Diabetes and Research and Yash Diabetes Specialties Centre (Swasthya Hospital), Ahmedabad during July 2010-November 2010. The subjects completed an interviewer-administered questionnaire. The questionnaire included variables, such as sociodemographic factors, family history of diabetes, behavioural profile, risk profile (glycaemic status, hypertension, and obesity), and diet-related history (consumption of diabetic diet, consumption of low fat/skimmed milk, method of cooking, and sources for diet advice). Blood pressure, body mass index, glycosylated haemoglobin (HbA1c) level, and fasting lipid profile were measured. All analyses including multivariate logistic regression were conducted using SPSS, version 11.5. In total, 399 T2DM subjects (65\% male, 35\% female) with mean age of $53.16 \pm 7.95$ years were studied. Although $73 \%$ of T2DM subjects were consuming diabetic diet, the good glycaemic control (HbA1c level $<7 \%$ ) was achieved only in $35 \%$ of the subjects. The majority $(75 \%)$ of the subjects had a positive family history of diabetes, and $52 \%$ were obese. In $77 \%$, the main source of dietary advice was doctor. In 36\%, the main methods of cooking were: boiling and roasting. The final multivariate model showed that visit to dietician, level of education, intake of low fat, and family history of diabetes were independent predictors for diabetic diet consumption among T2DM subjects. However, longitudinal and cohort studies are required to establish the association between consumption of diabetic diet and glycaemic control.
\end{abstract}

Key words: Cross-sectional study; Diet; Glycaemic control; Glycosylated haemoglobin; Obesity; Type 2 diabetes mellitus; India

\section{INTRODUCTION}

Type 2 diabetes mellitus (T2DM) is a chronic disease associated with high morbidity and mortality worldwide (1), and India is no exception $(2,3)$. Currently, India is facing a three-fold rise in the prevalence of diabetes in urban as well as in rural area (4). Subjects with T2DM are at high risk of developing micro-vascular and macro-vascular com-

Correspondence and reprint requests:

(Soft copy will be available from the authors)

Dr. Suresh Kumar Rathi

F-102, Aalekh Complex

8 Amravati Society, Near Yash Complex

Gotri Road, Vadodara

Gujarat

India 390021

Email: rathisj07@gmail.com plications; hence, the need for preventive action is widely acknowledged (5). The fundamentals of diabetes control largely depend upon drug therapy and lifestyle measures (increased physical activity and restriction of energy intake/diabetic diet) (6). Improved glycaemic control may reduce the development and progression of diabetic complications to some extent (7). Wealth of information is available on improving glycaemic control and decrease glycosylated haemoglobin (HbA1c) up to $2 \%$ through diet control (8-10). Coupled with this, appropriate dietary practices play a vital role in treating diabetes mellitus and, to some extent, prevent the complications of diabetes by improving risk factor profile. Strong body of evidence suggests that role of specific dietary factors remain uncertain; however, obesity and high intake of fat are associated with increased risk of diabetes (11-14). 
Despite the importance of diet in the management of T2DM, diabetic subjects are often unaware of the importance in ensuring glycaemic control (15). On the other hand, lack of dietary compliance is a major limiting factor in achieving glycaemic control in T2DM. Studies revealed that generally patients fail to adhere to dietary recommendations $(16,17)$. Hence, the present study aimed at providing the profile of the factors associated with consumption of diabetic diet among T2DM subjects from western India as an impetus for further exploration of the sociocultural and subject-related factors affecting the outcomes of T2DM care that, in turn, will lead to redefine the diabetes control and prevention strategies in this region.

\section{MATERIALS AND METHODS}

\section{Study setting}

A hospital-based cross-sectional study was conducted during July 2010-November 2010 in Ahmedabad district of Gujarat state, India. Ahmedabad is the commercial hub of the Gujarat state with an approximate population of six million.

\section{Study population}

The study population comprised diabetic subjects. We required them to be at least 40 years of age, have been diagnosed with T2DM for at least one year before enrollment for the study and, above all, it was a prerequisite for subjects to attend the Department of Diabetology, All India Institute of Diabetes and Research and Yash Diabetes Specialities Centre (Swasthya Hospital) during the study period.

\section{Sample-size and sampling method}

A sample-size of 405 was obtained by using parameter estimation method with $5 \%$ precision around the point estimate (an expected diabetic diet consumption level of 50\%) with 95\% confidence level. The calculated minimum sample-size was inflated by $5 \%$ to account for anticipated non-response from subjects.

On an average, there are at least 40 known diabetes cases reporting to OPD, and the monthly load of known diabetics will be around 900-1,000. Hence, during the study period of five months, the cases will be around 4,500-5,000. The study subjects were selected through systematic random sampling strategy for 4,000 study subjects (on conservative side) who reported to the OPD. Selection of the first case was done from within the first 10 subjects (in our case, it was number 6), followed by adding 10 to the number till the required sample-size of 405 was achieved.

\section{Procedure for data collection}

After recruitment of the subjects based on selection criteria and obtaining informed consent, the details of the study methodology were explained to them; a detailed history, including data on age, sex, education, occupation, smoking status, alcohol consumption, diabetic diet, method of cooking, and source of advice regarding diet, were recorded on a close-ended proforma. Diabetic diet was defined as a dietary adjustment for patients with diabetes mellitus intended to decrease the need of insulin or oral hypoglycaemic agents to avoid wide fluctuations in plasma glucose levels and to control weight by adjusting caloric and carbohydrate intake. Diabetic diet usually contains low-glycaemic index food, with similar amount of protein, complex carbohydrates, fibres, and unsaturated fatty acids as in food for general public. Diabetic diet was evaluated by dietary recall of the last 3 days, including timings, quantity of each meal and snacks, frequency of extra meal and food consumed from outside home, and the calculated average calorie consumed per day. All the subjects were also interviewed regarding history of hypertension. A general physical examination was also performed.

\section{Measurements}

All anthropometric measurements were recorded using standardized procedures. Study subjects also underwent various clinical tests, such as blood tests for plasma glucose, glycosylated haemoglobin (HbA1c), and lipid levels. Blood samples were collected after ensuring 12 hours of overnight fasting. Total lipids, triglycerides (TG), and high-density lipoprotein-cholesterol (HDL-C) levels were estimated in serum, using kits (End Point Assay with Liquid Clearing Factor-LCF, Span Diagnostics Ltd. India). Low-density lipoprotein-cholesterol (LDL-C) was calculated using the Friedewald formula: LDLC+TC-[HDL-C-(TG in mg/dL/5)] (18).

The current status of diabetes mellitus was measured using the criteria established by the American Diabetes Association (19), i.e. a medical record indicating either a fasting plasma glucose (FPG) level of $>7.0 \mathrm{mmol} / \mathrm{L}$ or $\geq 126 \mathrm{mg} / \mathrm{dL}$ after a minimum 12 hour fasting, or 2-hour post-glucose level (oral glucose tolerance test) of $>11.1 \mathrm{mmol} / \mathrm{L}$ or $\geq 200 \mathrm{mg} /$ $\mathrm{dL}$ on more than one occasion, with symptoms of diabetes. 
Blood pressure was recorded after the subjects had rested for at least ten minutes. The equipment was mercury sphygmomanometer (Diamond Deluxe BP apparatus, Pune, India). The machine was regularly inspected and validated. An appropriatelysized cuff (cuff bladder encircling at least $80 \%$ of the arm) was used for ensuring accuracy. It was applied on the right arm. The stethoscope bell was placed lightly over the brachial artery, and the blood pressure was recorded to the nearest $2 \mathrm{mmHg}$, reading from the top of the mercury meniscus. Systolic blood pressure (SBP) was recorded at the first appearance of two or more Korotkoff sounds and the disappearance of Korotkoff sound (onset of phase 5) was used for defining the diastolic blood pressure (DBP). Two readings were taken ten minutes apart, and mean of the two was considered the actual blood pressure. Hypertension was diagnosed based on the drug treatment for hypertension or if the blood pressure was $>130 / 80 \mathrm{mmHg}$ according to the Joint National Committee-7 (JNC-VII) criteria for diabetics $(20,21)$. The study subjects were classified into two groups, based on the history of antihypertensive drugs. The study subjects in group one were defined as not taking drugs for hypertension, were without past history of hypertension with normal blood pressure at the time of study or were detected for the first time to have hypertension, and known cases of hypertension not taking antihypertensive drugs. In group two, the study subjects were defined as taking drugs for hypertension, were having either hypertension in control with drugs or uncontrolled blood pressure even with drugs.

Body mass index (BMI) values for Indians were defined according to the recommendations by Indian Council of Medical Research. A study subject was considered to be obese if BMI was $\geq 25 \mathrm{~kg} / \mathrm{m}^{2}$ and overweight when BMI was 23-24.9 kg/m² (22).

Glycosylated haemoglobin (HbA1c) was measured by the high-pressure liquid chromatography (HPLC) method, using the variant machine (BIORAD, Hercules, California, USA). Reference nondiabetic range is $4.0-6.0 \%$. Control sera were included in each batch of samples analyzed. The criterion for glycaemic status was $<7 \%$ (good control), $7-8 \%$ (suboptimal control), 8-9\% (inadequate control), and $>9 \%$ (uncontrolled) (23).

\section{Data analysis}

Data were analyzed using the SPSS software (version 11.5). Means, standard deviations, and percentages were used for descriptive analysis. Student's $t$-test was used for testing the significance of differences between the mean values of two continuous variables. Univariate logistic regression analysis was conducted by comparing the outcome variable (consuming diabetic diet) with each independent variable of interest (age, sex, visiting dietician, level of education, occupation, glycaemic status, duration, and family history of diabetes), using odds ratio (OR) and their 95\% confidence intervals (CI). Likelihood ratio test was used in estimating odds ratio and 95\% CI for all associations of interest. Multivariate logistic regression analysis was performed to adjust for simultaneous effects of multiple factors or to control the effects of confounding factors on the outcome variable. The logistic regression model was used because the dependent variable was dichotomous (24)either a diabetic subject was consuming diabetic diet or not consuming diabetic diet. The criteria for inclusion of factors in the multivariate analysis were: all variables from the univariate analysis with a $\mathrm{p}$ value of $\leq 0.1$, along with all the variables of known biological importance. To assess the importance of each variable included in the model, Wald statistic for each variable was used. The parameters of the logistic regression model were estimated by the maximum likelihood method. The adjusted odds ratios (ORs) and their 95\% confidence intervals (CIs) were computed using the estimates of parameters of final model. Selection of final model was based on parsimony, biological interpretability, and statistical significance. The probability (p) level of less than 0.05 was considered significant.

\section{Ethical approval}

The Institutional Review Board of the All India Institute of Diabetes and Research reviewed and approved the study protocol and instrument.

\section{RESULTS}

A sample of 405 diabetic subjects was enrolled. Of the total study population, 399 (98.5\%) had T2DM, and $6(1.5 \%)$ had type 1 diabetes mellitus. Hence, analysis was performed on 399 T2DM subjects. Of 399 T2DM, 65\% were male, and 96\% were literate. The study subjects were evenly distributed in four quartiles of age with mean of 53.16 \pm 7.95 years. Ninety-one percent (365/399) of the subjects were following the Hinduism religion (Table $1)$. The mean weight $(\mathrm{kg})$ and height $(\mathrm{cm})$ were $(69.04 \pm 10.50)$ and $(164.51 \pm 9.75)$ respectively. The mean duration of diabetes since diagnosis was $5.95 \pm 4.42$ years. 


\section{Risk and behaviour profile}

The findings of the study showed that 140 (35\%) had good glycaemic control (HbA1c <7\%). The findings showed the subjects had a mean BMI of $25.57 \pm 4.05$. Only $21 \%$ of the subjects were of normal weight; the majority were either overweight (BMI 23-24.99 kg/m², 24\%) or obese (BMI $\geq 25 \mathrm{~kg} /$ $\left.\mathrm{m}^{2}, 52 \%\right)$. About half (198/399) of the subjects had positive history of hypertension, and three-fourths (300/399) had positive family history of diabetes. Only $37 \%$ of the subjects were performing self-testing for blood sugar. The study also revealed that 95 (24\%) of the subjects were smokers, and 32 (8\%) were consuming alcohol (Table 1).

\begin{tabular}{|c|c|c|}
\hline Characteristics & $\begin{array}{l}\text { Number } \\
(\mathrm{n}=399)\end{array}$ & $\begin{array}{l}\text { Percent- } \\
\text { age* }^{*}\end{array}$ \\
\hline \multicolumn{3}{|l|}{ Age (years) } \\
\hline Up to 47 & 109 & 27 \\
\hline$>47-52$ & 98 & 25 \\
\hline$>52-58$ & 102 & 25 \\
\hline$>58$ & 90 & 23 \\
\hline \multicolumn{3}{|l|}{ Sex } \\
\hline Male & 259 & 65 \\
\hline Female & 140 & 35 \\
\hline \multicolumn{3}{|l|}{ Marital status } \\
\hline Never married & 14 & 4 \\
\hline Ever married & 385 & 96 \\
\hline \multicolumn{3}{|l|}{ Religion } \\
\hline Hinduism & 365 & 91 \\
\hline Islam & 15 & 4 \\
\hline Christianity and others & 19 & 5 \\
\hline \multicolumn{3}{|l|}{ Level of education } \\
\hline No education & 14 & 4 \\
\hline Primary school & 84 & 21 \\
\hline Secondary school & 176 & 44 \\
\hline College level & 107 & 26 \\
\hline University level & 14 & 4 \\
\hline $\begin{array}{l}\text { Professional degree (CA, } \\
\text { MBA, MBBS, etc.) }\end{array}$ & 4 & 1 \\
\hline \multicolumn{3}{|l|}{ Occupation } \\
\hline Govt. service & 8 & 2 \\
\hline Professional & 12 & 3 \\
\hline Private service & 87 & 22 \\
\hline Business & 116 & 29 \\
\hline Household work/retired & 176 & $\begin{array}{c}44 \\
\text { Contd. }\end{array}$ \\
\hline
\end{tabular}

\begin{tabular}{|c|c|c|}
\hline Characteristics & $\begin{array}{l}\text { Number } \\
(\mathrm{n}=399)\end{array}$ & $\begin{array}{l}\text { Percent- } \\
\text { age* }^{*}\end{array}$ \\
\hline \multicolumn{3}{|l|}{ Type of diabetes } \\
\hline T2DM & 399 & 100 \\
\hline \multicolumn{3}{|l|}{ Mode of diagnosis of diabetes } \\
\hline Symptomatic & 373 & 93 \\
\hline At screening & 23 & 6 \\
\hline Incidental & 3 & 1 \\
\hline \multicolumn{3}{|l|}{ Duration of diabetes (years) } \\
\hline $1-2$ & 105 & 26 \\
\hline$>2-5$ & 120 & 30 \\
\hline$>5-9$ & 90 & 23 \\
\hline$>9$ & 84 & 21 \\
\hline \multicolumn{3}{|l|}{ Glycaemic status (\%) } \\
\hline$<7$ (good control) & 140 & 35 \\
\hline 7-8 (suboptimal control) & 120 & 30 \\
\hline$>8-9$ (inadequate control) & 80 & 20 \\
\hline >9 (uncontrolled) & 59 & 15 \\
\hline \multicolumn{3}{|l|}{ Family history of diabetes } \\
\hline Positive & 300 & 75 \\
\hline Negative & 99 & 25 \\
\hline \multicolumn{3}{|l|}{ Body mass index (BMI) group } \\
\hline $\begin{array}{l}\text { Underweight } \\
\left(<18.5 \mathrm{~kg} / \mathrm{m}^{2}\right)\end{array}$ & 13 & 3 \\
\hline Normal (18.5-22.9 kg/m²) & 83 & 21 \\
\hline $\begin{array}{l}\text { Overweight } \\
\left(23.0-24.9 \mathrm{~kg} / \mathrm{m}^{2}\right)\end{array}$ & 95 & 24 \\
\hline Obese $\left(\geq 25.0 \mathrm{~kg} / \mathrm{m}^{2}\right)$ & 208 & 52 \\
\hline \multicolumn{3}{|l|}{ Self-monitoring blood sugar } \\
\hline Yes & 146 & 37 \\
\hline No & 253 & 63 \\
\hline \multicolumn{3}{|l|}{ Hypertension } \\
\hline Present & 198 & 50 \\
\hline Not present & 201 & 50 \\
\hline \multicolumn{3}{|l|}{ Smoker } \\
\hline Yes & 95 & 24 \\
\hline No & 304 & 76 \\
\hline \multicolumn{3}{|l|}{ Alcohol consumption } \\
\hline Yes & 32 & 8 \\
\hline No & 367 & 92 \\
\hline
\end{tabular}

There was a significant $(\mathrm{p}<0.05)$ difference between male and female subjects with respect to mean weight (male $=71.101 \pm 9.809$ $\mathrm{kg}$, female $=65.165 \pm 10.498 \mathrm{~kg})$, height (male $=169.83 \pm 6.875 \mathrm{~cm}$, female $=154.66 \pm 5.831 \mathrm{~cm}$ ), and BMI (male $=24.64 \pm 3.523$, female $=27.30 \pm 4.418$ ) (Table 2). 


\begin{tabular}{|c|c|c|c|}
\hline \multirow{2}{*}{ Characteristics } & \multicolumn{2}{|c|}{ Mean \pm SD } & \multirow{2}{*}{$\mathrm{p}$ value } \\
\hline & Male & Female & \\
\hline Age (years) & $52.95 \pm 8.136$ & $53.55 \pm 7.602$ & 0.475 \\
\hline Weight $(\mathrm{kg})$ & $71.101 \pm 9.809$ & $65.165 \pm 10.498$ & $<0.001$ \\
\hline Height $(\mathrm{cm})$ & $169.83 \pm 6.875$ & $154.66 \pm 5.831$ & $<0.001$ \\
\hline Body mass index $\left(\mathrm{kg} / \mathrm{m}^{2}\right)$ & $24.64 \pm 3.523$ & $27.30 \pm 4.418$ & $<0.001$ \\
\hline Duration of diabetes (years) & $6.027 \pm 4.353$ & $5.828 \pm 4.558$ & 0.669 \\
\hline \multicolumn{4}{|c|}{ Blood pressure without drugs $(\mathrm{n}=201)$} \\
\hline Systolic (mmHg) & $130.45 \pm 14.076$ & $132.39 \pm 14.639$ & 0.350 \\
\hline Diastolic (mmHg) & $83.15 \pm 7.261$ & $83.17 \pm 8.166$ & 0.986 \\
\hline \multicolumn{4}{|c|}{ Blood pressure with drugs $(\mathrm{n}=198)$} \\
\hline Systolic (mmHg) & $135.34 \pm 16.845$ & $134.93 \pm 15.936$ & 0.861 \\
\hline Diastolic (mmHg) & $83.14 \pm 9.469$ & $84.10 \pm 8.207$ & 0.598 \\
\hline \multicolumn{4}{|l|}{ Lipid profile ( $\mathrm{n}=389)$} \\
\hline LDL cholesterol (mg/dL) & $111.19 \pm 36.297$ & $116.34 \pm 33.184$ & 0.172 \\
\hline HDL cholesterol (mg/dL) & $41.42 \pm 5.000$ & $42.74 \pm 6.029$ & 0.220 \\
\hline Triglycerides (mg/dL) & $187.93 \pm 118.826$ & $181.67 \pm 119.690$ & 0.623 \\
\hline Total lipids (mg/dL) & $714.46 \pm 167.240$ & $711.99 \pm 143.014$ & 0.884 \\
\hline
\end{tabular}

\section{Dietary practices}

Majority (73\%) of the subjects consuming diabetic diet were recommended by the family physicians/ dieticians. However, only 39\% reported that they had visited dietician since their diagnosis of diabetes, and only $2 \%$ reported counting calorie intake. Doctors/family physicians were reported to be the good source of advice regarding diet by $77 \%$ study population. The main method of cooking was: boiling and roasting (36\%). Majority (88\%) reported taking low fat or skimmed milk (Table 3).

Results of univariate analysis showed that visit to a dietician (OR=9.7, 95\% $\mathrm{CI}=4.898-19.465)$, secondary level of education $(\mathrm{OR}=2.6,95 \%$ $\mathrm{CI}=1.611-4.128)$, and low intake of fat $(\mathrm{OR}=2.6$, $95 \% \mathrm{CI}=1.385-4.760$ ) are significantly associated with consumption of diabetic diet among T2DM subjects. Family history of diabetes is marginally associated with consumption of diabetic diet among T2DM subjects (Table 4). However, in univariate analysis, not a single factor was significantly associated with glycaemic status.

The final multivariate logistic regression model revealed that compared to the subjects not consuming diabetic diet, those who consumed diabetic diet were more likely to visit dietician (adjusted $\mathrm{OR}=10.6$, 95\% CI=5.124-21.816), consume low fat (adjusted OR=2.2, 95\% CI=1.078-4.291), had higher level of education (adjusted $\mathrm{OR}=3.5$, 95\% $\mathrm{CI}=2.020-5.948)$, and have positive family history of diabetes (adjusted OR=1.8, 95\% CI=0.996-3.094) (Table 5).

\section{DISCUSSION}

Diabetes, literally a 'sweet' disease, is slowly but surely spreading around the world, and India today is home to one of the world's fastest-growing diabetic population (25). Hence, need for preventive actions through lifestyle modifications (diet control, physical exercise, etc.) would be widely given due importance (26).

The main factors observed in our study population were visit to dieticians, level of education, consumption of low fat/skimmed milk, and presence of family history of diabetes. Majority (88\%) of the study subjects were consuming low fat/skimmed milk, which differ from a study by Al-Kaabi et al. (23). The reason for discrepancy may be that our study subjects were more likely to seek dietary advice from family physician/dietician. Diet planning is the mainstay in the selfmanagement and control of T2DM (23). In the present study, $73 \%$ of the subjects were consuming diabetic diet, which differs from our previous report (27). This suggests that our study popula- 


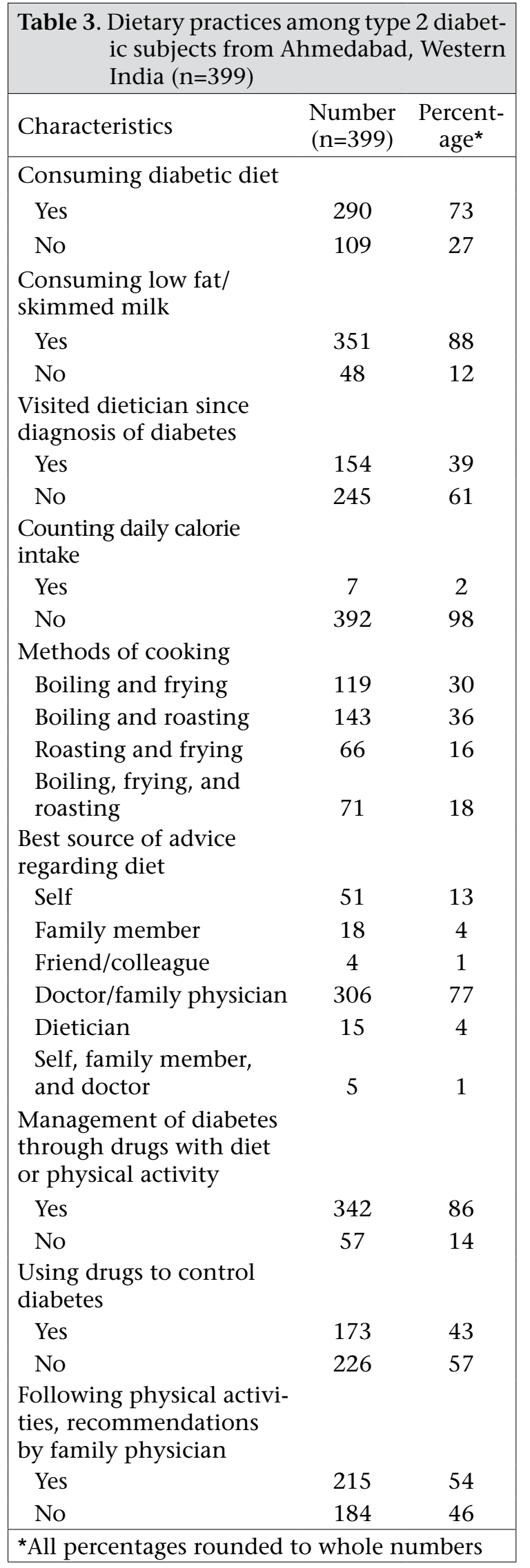

tion was seriously considering the dietary advice. The main sources of dietary advice were: family physicians (77\%) and dieticians (4\%) who had a minimal role in dietary advice; the finding is consistent with those of previous studies $(15,23)$. The possible explanation for this may be: easier access to family physicians than dieticians.

This study confirms our previous report regarding family history of diabetes among T2DM subjects (27). Result also showed that very few study subjects $(14 / 399)$ were illiterate. This is expected because sample of this study was drawn from speciality hospital located in urban area.

Our findings for obesity (52\%) among T2DM subjects are consistent with previous reports (28-31). Findings of this study also confirm the previous reports of low level of self-monitoring of blood sugar (32). This suggests that there might be a lack of awareness of its importance in relation to control of diabetes.

In this study, only $35 \%$ subjects had good glycaemic control, which is supported by reports from Holmström et al. (34\%) and Al-Maskari et al. (38\%) (33-34). However, this study could not demonstrate any significant association between diabetic diet and glycaemic control, despite there is high parcentage of study subjects consuming diabetic diet. This suggests that our study subjects might have started consuming diabetic diet recently, which has insignificant impact on glycaemic status in short duration.

\section{Limitations}

The study has some weaknesses; only diet recall method was used for the last 3 days, and the study did not use any additional data on duration of diabetic diet consumption, which may either reduce or exaggerate the result of glycaemic control. This might be the reason behind insignificant association between diabetic diet and glycaemic control. Total reliance on the subjects regarding diabetic diet was another limitation. This is a hospital-based study from urban setup, which may not be representative of and applicable to general population. However, this could provide a reasonably precise and reliable estimate of factors associated with consumption of diabetic diet among T2DM subjects from western India. Such weaknesses may become a guide for future studies.

\section{Conclusions}

This study revealed that majority (73\%) of the subjects were consuming diabetic diet. The study also 


\begin{tabular}{|c|c|c|c|c|c|}
\hline \multirow[b]{2}{*}{ Variable } & \multicolumn{2}{|c|}{ Consuming diabetic diet } & \multirow[b]{2}{*}{ OR } & \multirow[b]{2}{*}{$(95 \% \mathrm{CI})$} & \multirow[b]{2}{*}{$\mathrm{p}$ value } \\
\hline & $\begin{array}{c}\text { Yes } \\
(\mathrm{n}=290)\end{array}$ & $\begin{array}{c}\text { No } \\
(\mathrm{n}=109)\end{array}$ & & & \\
\hline \multicolumn{6}{|l|}{ Age (years) } \\
\hline Up to 47 & 79 & 30 & 1.07 & $(0.575-1.989)$ & 0.831 \\
\hline$>47-52$ & 74 & 24 & 1.25 & $(0.655-2.394)$ & 0.496 \\
\hline$>52-58$ & 73 & 29 & 1.02 & $(0.546-1.914)$ & 0.944 \\
\hline$>58$ & 64 & 26 & 1 & - & \\
\hline \multicolumn{6}{|l|}{ Sex } \\
\hline Male & 189 & 70 & 1.04 & $(0.658-1.652)$ & 0.859 \\
\hline Female & 101 & 39 & 1 & - & \\
\hline \multicolumn{6}{|l|}{ Visit to dieticians } \\
\hline Yes & 144 & 10 & 9.7 & $(4.898-19.465)$ & $<0.001$ \\
\hline No & 146 & 99 & 1 & - & \\
\hline \multicolumn{6}{|l|}{ Level of education } \\
\hline No education & 6 & 8 & 0.48 & $(0.158-1.479)$ & 0.203 \\
\hline Up to secondary & 208 & 52 & 2.58 & $(1.611-4.128)$ & $<0.001$ \\
\hline Above secondary & 76 & 49 & 1 & - & \\
\hline \multicolumn{6}{|l|}{ Occupation } \\
\hline Housewifery/retired & 133 & 43 & 1.32 & $(0.771-2.260)$ & 0.312 \\
\hline Business & 82 & 34 & 1.03 & $(0.579-1.829)$ & 0.922 \\
\hline Service & 75 & 32 & 1 & - & \\
\hline \multicolumn{6}{|c|}{ Duration of diabetes (years) } \\
\hline $1-2$ & 69 & 36 & 0.81 & $(0.438-1.506)$ & 0.509 \\
\hline$>2-5$ & 97 & 23 & 1.78 & $(0.931-3.431)$ & 0.081 \\
\hline$>5-9$ & 65 & 25 & 1.10 & $(0.571-2.125)$ & 0.773 \\
\hline$>9$ & 59 & 25 & 1 & - & \\
\hline \multicolumn{6}{|c|}{ Family history of diabetes } \\
\hline Positive & 224 & 76 & 1.47 & $(0.901-2.411)$ & 0.123 \\
\hline Negative & 66 & 33 & 1 & - & \\
\hline \multicolumn{6}{|c|}{$\begin{array}{l}\text { Consuming low fat/skimmed } \\
\text { milk }\end{array}$} \\
\hline Yes & 264 & 87 & 2.56 & $(1.385-4.760)$ & 0.003 \\
\hline No & 26 & 22 & 1 & - & \\
\hline \multicolumn{6}{|l|}{ Glycaemic status (\%) } \\
\hline$<7$ & 99 & 41 & 1 & - & \\
\hline$\geq 7$ & 191 & 68 & 1.16 & $(0.736-1.838)$ & 0.517 \\
\hline
\end{tabular}

showed that visit to dieticians, level of education, consumption of low fat/skimmed milk, and presence of family history of diabetes were the main factors associated with consumption of diabetic diet. Self-monitoring of blood sugar is done by few subjects (37\%).

\section{Recommendations}

Based on our findings we recommend the following:

- Visit to a dietician must be emphasized

- Frequent self-monitoring of blood sugar level 


\begin{tabular}{|lccc|}
\hline \multicolumn{4}{|c|}{$\begin{array}{l}\text { Table } \\
\text { hospital-based T2DM subjects from Ahmedabad, Western India (n=399) }\end{array}$} \\
\hline Variable & AOR & $95 \%$ CI & p value \\
\hline Visit to dieticians & 10.6 & $5.124-21.816$ & $<0.001$ \\
$\quad$ Yes & 1 & - & \\
No & & & 0.606 \\
Level of education & 0.7 & $0.215-2.453$ & $<0.001$ \\
$\quad$ No education & 3.5 & $2.020-5.948$ & \\
Up to secondary & 1 & - & 0.051 \\
Above secondary & & & \\
Family history of diabetes & 1.8 & $0.996-3.094$ & 0.030 \\
$\quad \begin{array}{l}\text { Positive } \\
\text { Negative }\end{array}$ & 1 & - & \\
Consuming low fat/skimmed milk & & $1.078-4.291$ & \\
Yes & 2.2 & - & \\
No & 1 & & \\
\hline AOR=Adjusted odds ratio; CI=Confidence interval & & \\
\hline
\end{tabular}

needs to be taught and encouraged because it is associated with good glycaemic control.

Despite limitations, this study underlines the need for further investigation in India through longitudinal and cohort study designs to establish the association between consumption of diabetic diet and glycaemic control

\section{ACKNOWLEDGEMENTS}

The study was supported by All India Institute of Diabetes and Research, Ahmedabad, India. The authors would like to express their sincere thanks to all the diabetic subjects who participated in the study. They would also like to thank Dr. W.Q. Shaikh for reviewing the manuscript.

\section{RERFERENCES}

1. van Dam RM, Hu FB. Coffee consumption and risk of type 2 diabetes: a systematic review. JAMA 2005;294:97-104.

2. Mudaliar S. New frontiers in the management of type 2 diabetes. Indian J Med Res 2007;125:275-96.

3. Wild S, Roglic G, Green A, Sicree R, King H. Global prevalence of diabetes: estimates for the year 2000 and projections for 2030. Diabetes Care 2004;27:104753.

4. Ebrahim S, Kinra S, Bowen L, Andersen E, Ben-Shlomo Y, Lyngdoh T et al.; Indian Migration Study group. The effect of rural-to-urban migration on obesity and diabetes in India: a cross-sectional study. PLoS Med 2010;7:e1000268.

5. Mohan V, Deepa M, Deepa R, Shanthirani CS, Farooq $\mathrm{S}$, Ganesan A et al. Secular trends in the prevalence of diabetes and impaired glucose tolerance in urban
South India-the Chennai Urban Rural Epidemiology Study (CURES-17). Diabetologia 2006;49:1175-8.

6. Hu FB, Manson JE, Stampfer MJ, Colditz G, Liu $\mathrm{S}$, Solomon CG et al. Diet, lifestyle, and the risk of type 2 diabetes mellitus in women. $N$ Engl J Med 2001;345:790-7.

7. Kumpatla S, Medempudi S, Manoharan D, Viswanathan V. Knowledge and outcome measure of HbA1c testing in Asian Indian patients with type 2 diabetes from a tertiary care center. Indian J Community Med 2010;35:290-3.

8. Pastors JG, Warshaw H, Daly A, Franz M, Kulkarni K. The evidence for the effectiveness of medical nutrition therapy in diabetes management. Diabetes Care 2002;25:608-13.

9. Pi-Sunyer FX, Maggio CA, McCarron DA, Reusser ME, Stern JS, Haynes RB et al. Multicenter randomized trial of a comprehensive prepared meal program in type 2 diabetes. Diabetes Care 1999;22:191-7.

10. Kulkarni K, Castle G, Gregory R, Holmes A, Leontos $\mathrm{C}$, Powers $\mathrm{M}$ et al.; The Diabetes Care and Education Dietetic Practice Group. Nutrition Practice Guidelines for Type 1 Diabetes Mellitus positively affect dietitian practices and patient outcomes. J Am Diet Assoc 1998;98:62-70.

11. Ni Mhurchu C, Parag V, Nakamura M, Patel A, Rodgers A et al.; Asia Pacific Cohort Studies Collaboration. Body mass index and risk of diabetes mellitus in the Asia-Pacific region. Asia Pac J Clin Nutr 2006;15:12733.

12. Hu FB, van Dam RM, Liu S. Diet and risk of Type II diabetes: the role of types of fat and carbohydrate. Diabetologia 2001;44:805-17.

13. Schulze MB, Manson JE, Willett WC, Hu FB. 
Processed meat intake and incidence of Type 2 diabetes in younger and middle-aged women. Diabetologia 2003;46:1465-73.

14. Fung TT, Schulze M, Manson JE, Willett WC, Hu FB. Dietary patterns, meat intake, and the risk of type 2 diabetes in women. Arch Intern Med 2004;164:223540.

15. Abioye-Kuteyi EA, Ojofeitimi EO, Ijadunola KT, Fasanu AO. Assessment of dietary knowledge, practices and control in type 2 diabetes in a Nigerian teaching hospital. Niger J Med 2005;14:58-64.

16. Monnier L, Grimaldi A, Charbonnel B, Iannascoli F, Lery T, Garofano A et al.; Mediab. Management of French patients with type 2 diabetes mellitus in medical general practice: report of the Mediab observatory. Diabetes Metab 2004;30:35-42.

17. Rivellese AA, Boemi M, Cavalot F, Costagliola L, De Feo P, Miccoli R et al.; The Mind.it Study Group(FoRiSID). Dietary habits in type II diabetes mellitus: how is adherence to dietary recommendations? Eur J Clin Nutr 2008;62:660-4.

18. Chen Y, Zhang X, Pan B, Jin X, Yao H, Chen B et al. A modified formula for calculating low-density lipoprotein cholesterol values. Lipids Health Dis 2010;9. 5 p. (http://www.ncbi.nlm.nih.gov/pmc/articles/ PMC2890624/pdf/1476-511X-9-52.pdf).

19. American Diabetes Association. Diagnosis and classification of diabetes mellitus. Diabetes Care 2006;29(Suppl 1):S43-8.

20. Reddy KS, Prabhakaran D, Chaturvedi V, Jeemon P, Thankappan KR, Ramakrishnan L et al. Methods for establishing a surveillance system for cardiovascular diseases in Indian industrial populations. Bull World Health Organ 2006;84:461-9.

21. Lenfant C, Chobanian AV, Jones DW, Roccella EJ; Joint National Committee on the Prevention, Detection, Evaluation, and Treatment of High Blood Pressure. Seventh report of the Joint National Committee on the Prevention, Detection, Evaluation, and Treatment of High Blood Pressure (JNC 7): resetting the hypertension sails. Hypertension 2003;41:1178-9.

22. Misra A, Chowbey P, Makkar BM, Vikram NK, Wasir JS, Chadha D et al.; Concensus Group. Consensus statement for diagnosis of obesity, abdominal obesity and the metabolic syndrome for Asian Indians and recommendations for physical activity, medical and surgical management. J Assoc Physicians India 2009;57:163-70.
23. Al-Kaabi J, Al-Maskari F, Saadi H, Afandi B, Parkar H, Nagelkerke N. Assessment of dietary practice among diabetic patients in the United Arab Emirates. Rev Diabet Stud 2008;5:110-5.

24. Aldrich JH, Nelson FD. Linear probability, logit and probit models. Beverly Hills, CA: Sage, 1984. 96 p. (SAGE University Paper Series: Quantitative Applications in the Social Sciences. Vol. 45).

25. Deepa M, Pradeepa R, Rema M, Mohan A, Deepa R, Shanthirani S et al. The Chennai Urban Rural Epidemiology Study (CURES)—study design and methodology (urban component) (CURES-I). J Assoc Physicians India 2003;51:863-70.

26. Yang K, Lee YS, Chasens ER. Outcomes of health care providers' recommendations for healthy lifestyle among U.S. adults with prediabetes. Metab Syndr Relat Disord 2011;9:231-7.

27. Patel M, Patel IM, Patel YM, Rathi SK. A hospital-based observational study of type 2 diabetic subjects from Gujarat, India. J Health Popul Nutr 2011;29:265-72.

28. Mayer-Davis EJ, Costacou T. Obesity and sedentary lifestyle: modifiable risk factors for prevention of type 2 diabetes. Curr Diab Rep 2001;1:170-6.

29. Lieberman LS. Dietary, evolutionary, and modernizing influences on the prevalence of type 2 diabetes. Annu Rev Nutr 2003;23:345-77.

30. Bener A, Al-Suwaidi J, Al-Jaber K, Al-Marri S, Elbagi IE. Epidemiology of hypertension and its associated risk factors in the Qatari population. J Hum Hypertens 2004;18:529-30.

31. Musaiger AO, Al-Mannai MA. Social and lifestyle factors associated with diabetes in the adult Bahraini population. J Biosoc Sci 2002;34:277-81.

32. Saadi H, Carruthers SG, Nagelkerke N, Al-Maskari F, Afandi B, Reed R et al. Prevalence of diabetes mellitus and its complications in a population-based sample in Al Ain, United Arab Emirates. Diabetes Res Clin Pract 2007;78:369-77.

33. Holmström IM, Rosenqvist U. Misunderstandings about illness and treatment among patients with type 2 diabetes. J Adv Nurs 2005;49:146-54.

34. Al-Maskari F, El-Sadig M. Prevalence of risk factors for diabetic foot complications. BMC Fam Pract 2007;8:59. 